\title{
Building Virtual Communities for Research Collaboration
}

\author{
m.c. schraefel, Janet Ho, and Mark Chignell \\ Knowledge Media Design Institute, University of Toronto \\ Michael Milton \\ Bell Canada University Laboratories
}

\begin{abstract}
This paper discusses the problem of how to grow and evolve virtual infrastructures that support the development and growth of geographically dispersed research communities. It will describe ongoing research into personalization within a collaborative environment intended as a "virtual campus". As part of this research we will provide initial reports on a project that is developing collaborative workspaces for dispersed research teams, and we will review relevant literature pertaining to the use of online collaborative workspaces to build virtual communities.
\end{abstract}

\section{Introduction}

In an increasingly networked world it is advantageous for researchers to be able to collaborate at a distance. New kinds of collaborative tools are needed to make this possible. Dispersed interdisciplinary teams need collaborative tools so that they can jointly address the complex problems that societies and organizations face. In many organizations, people working in different disciplines are separated in different buildings, often on different campuses, or in different cities. Thus the demand for virtual collaboration is increasing at the same time that bandwidth and networking constraints are being removed. The chief constraints to virtual collaboration now consist of the applications and interfaces that are available, and the ability of organizations to motivate and train researchers to use these tools effectively as they become available.

Collaboration requires shared information and effective communication. Researchers located across a campus, with different schedules, have difficulty meeting physically. Often meetings are delayed by days if not weeks while key people are out of town. Moreover, lack of access to key documents in a timely fashion means that work may be duplicated, or subtasks may be neglected as they "fall between the cracks" of the group or team.

Technological advances, and the Internet, help to gather researchers in to a single virtual work space. The implementation of a virtual community infrastructure allows research groups to make schedules, and monitor timelines. This infrastructure also provides a workspace within which to present plans, proposals, deliverables, and other documents to the rest of the research team. However, different project groups will have different work habits as different companies have different organizational cultures. Thus each project group should have its own personalized virtual workspace to facilitate information flow and to improve work habits. Different types of multimedia interface will be required for the various personalized versions of the virtual workspace.

Our work reflects an approach to virtual community building as an iterative design process, closely tied to the direct requests and feedback of the group it seeks to serve. We have become aware of the need for contextual analysis of diverse research group requirements for collaboration and communication. For instance, it may be important at some point in our Lab's future to have the virtual world be able to reach into the real world to help connect researchers real time (via web conferencing, for instance). For now it is, we believe, of primary importance to build in the opposite direction: to build from the real world into the virtual. Then, we postulate, with the space tied to a given set of actual and actualized needs, we can improve the likelihood of continued participation in this space. Such participation in our case is important since our work is interdisciplinary, and although largely based within one University, there is no single physical lab, and we are physically spread across a variety of buildings. 


\section{Virtual Communities}

\subsection{Virtual environments and virtual communities at work}

Virtual workplace environments allow people to work separately while still experiencing a mutual sense of presence. Using a standard web site, for instance, team member A might know that team member B exists virtually: from that site it would then be easy to see that B has a web site, email address and list of materials available about B's work. Communities, however, may be said to extend beyond the simple notion of "presence". Communities contain individuals who form relationships, and who have a sense of group membership and belonging within their group [1]. We wish to consider how infrastructure can be designed to support and enhance this relationbuilding attribute of community in the virtual domain.

In the context of research work groups, work groups members can access and approach each other through a variety of Internet based methods, e.g.:

- communal notice boards on a web site,

- group-based email for discussion or information sharing,

- shared media archives for asynchronous access to project materials by group members.

The first step to understand the role of infrastructure will be to understand the components of possible relations within the virtual environment workspace $^{1}$. Relations are constructed among users, groups and interaction environments. Environments can be: the overall Lab or Center, the Projects within that Lab, and individual research space (IRS). Within these spaces are, obviously, relations as Lab members, Project members, individual researchers, and support staff.

Entities at Rest: Identities and relations within the virtual workspace. At the top, or Lab level, the Lab needs to be able to represents itself as a cohesive entity in the virtual work space. Similarly, the projects within the lab represent themselves as holistic entities collaborating to support the Lab's mission. The Lab is then represented to its members and the broader community through activities such as

\footnotetext{
${ }^{1}$ Note, we use the term virtual environment work space rather than virtual community since we will suggest that virtual communities cannot be brought into being, but can only evolve from quality of interaction/tool use within an environment.
}

sharing results, posting updates and reviews of work in progress, and milestones reached, etc.

At the Project level, the virtual workspace provides information resources to its members on a project by project basis. In our research, we wish to see how this virtual space for posting results can be come dynamic and valuable enough to enhance the researcher's practice such that the researcher is motivated to work collaboratively in this space.

Individual researchers must initially create and project a 'sense of self' with respect to a virtual community and the individual work networks within that community. These projections of self need to be tailored to each relationship and potentially held secure from each other, but they are open to rationalization by the originator. The individual must also be able to create a context for collaboration for each relationship and populate it with tools which suit that individual, the sub-community involved in the relationship, and the task (possibly with individual users applying different tools to a common database of content). Similarly, users need to be able to monitor, control and audit their contributions in each relationship and across the community, as well as to position and evolve each 'self'. Thus, the individual must be able to directly influence issues of trust, rather than be required to trust in advance.

Access to tools and flexible ways of working within environments are critical for work by members within the lab. However the creation or selection of these tools may not be solely the responsibility of a member at the time of joining the group. For the initial stages of community growth, we suspect that such demands on an individual user are too onerous. Rather than community, isolation or avoidance of the space may result. Therefore, key issues for prospective users include: how well the environment will integrate with tools already familiar to the user; how it will support the user acquiring new tools; how it may be able to recommend support strategies to the user/researcher. In other words, infrastructure is not only about available tools, but about enhanced integration of existing user experience/tools, and environment support for supplementary tools.

There are a lot of explicit and implicit policy and cultural barriers that emerge as one considers the issues of individual/group interaction in a constrained environment as described above. For example, differences across the community in ownership, transference and compensation for intellectual capital need to be accommodated. Observation of how existing research communities adapt to email and the Internet and use basic tools to enhance collaboration can help in guiding the design of virtual workspaces that encourage community-building. 
Koku, Nazer, and Wellman [2] recently studied a group of researchers in the early stages of building both a physical and a virtual community. They referred to this evolving community by the pseudonym "Technet". Technet is a multidisciplinary research organization that relies on personal relationships between researchers, and various seminars and social events to create cohesion and a sense of community (since it has no "bricks and mortar" home). In addition, there is ongoing work in Technet to develop a virtual community through the development initially of a Website and ultimately of a suite of functionalities within a collaborative workspace, or "Virtual Campus".

In the interviews performed by Koku, Nazer and Wellman [2] members stated that they found more "kindred souls" in Technet then they did in their home departments. This creates a strong motivation for building a virtual community that can create virtual presence amongst these kindred souls. This requirement is important in organizations like Technet where opportunities for face-to-face interaction are limited, but where collaboration and community-building are highly valued.

The Technet website provides a shared space for collaboration in the virtual community. There is a "Chat" section in the website where members can discuss various topics. Group members can post important notices, lecture series, or general discussion topics. This workspace permits real-time access by all registered group members. However, individual group members are not allowed to create a separate forum.

For Technet, postings of the latest events and course announcements through the links "What's New", "Events", and "Courses" pages were made by the Webmaster. There was no facilitated space for group members to post work-in-progress documents or spontaneous ideas. It might improve community building in this case if there was more shared workspace for the group members to 'play' around in, test their ideas in, and get feedback from other members. Thus, the virtual environment that we are constructing is less centralized, letting users and research groups build and populate the structures that they want. In this way the virtual community is free to grow and evolve based on the actions and interests of the various members of that community.

\subsection{Community-Building Tools and Techniques}

Effective communication among project group members is a key element to success for working collaboratively over the virtual campus. Virtual space supplements, rather than replaces, other more traditional means of group communication [1]. If the communication in the virtual environment is not transparent enough, and group members revert to the more traditional means of group communication, it will defeat the purpose of this virtual campus. Working collaboratively over networks is ultimately about facilitating real communication [3] enhanced by a virtual presence.

To enable teams of people to work more efficiently together, tools that help to share information are necessary. The tools for these virtual communities should contain threaded discussion features, email, calendering and scheduling, voting utility, chat space, customizable interface, newsgroup, document management, real-time conferencing etc. [4],[5].

One of the major components that contribute to a group member's experiences in virtual environment is the communication and collaboration involved [6]. Virtual communities members are expected to communicate and interact with others with the help of the components available in the community. Most virtual communities provide a central meeting place on the Internet where all of a project's communications and documents can reside [5]. Group members can go to the community's central web page, where it will be the group's common workspace. The central web page contains the group's mission statement, important deadlines and instructions; members are also able to leave e-mail for others, initiate or join a discussion or real-time conference, and post documents.

Communication and collaboration are the basis of virtual communities, but they are slightly different. Collaboration requires a higher order of involvement as well as a different approach to sharing and creating information. "Collaboration creates a shared meaning about a process, a product, or an event" [7]. In virtual communities, group members communicate what they think and want to do, then they collaborate by solving the created problem or discover something within the group's expertise, time, money, competition and conventional wisdom.

Researchers at BT Laboratories have recommended the following key steps for supporting communication within a collaborative virtual environment [6]:

- support group members in their decision to communicate;

- Let users choose among a range of communication 'types';

- provide the necessary tools within the virtual world to initiate communication as if users are in the real world

- support user requirements such as use of gestures during communication mediated within the virtual world. 
Communication and collaboration within a virtual world is an example of a socio-technical system. Like other socio-technical systems, human coordination and policy-setting can be just as important as the technologies and tools that are used. Policies for how communication is handled between group members is particularly important when there are a range of media that can be used for different communication tasks.

There should be some agreements among the group as to which is the formal way to deal with various forms media (e-mail, phone messages, voice mail, fax). For example, should the group post messages through the group's website, or through email or other forms of media? Should group members post documents or attached files in email? It is therefore necessary to figure out the group's preferences around the use of different communications media - email, telephone, voice mail, etc. [8].

Johansen defined a $2 \times 2$ matrix that differentiates groupware technologies in terms of their abilities to bridge time and bridge space [8] [9] (See Table 1).

\begin{tabular}{|l|l|l|}
\hline & $\begin{array}{l}\text { Same place (co- } \\
\text { located) }\end{array}$ & $\begin{array}{l}\text { Different place } \\
\text { (distributed) }\end{array}$ \\
\hline $\begin{array}{l}\text { Same time } \\
\text { (synchron } \\
\text { ous) }\end{array}$ & $\begin{array}{l}\text { Face-to-face } \\
\text { meetings: e.g. } \\
\text { public computer } \\
\text { displays, } \\
\text { electronic } \\
\text { meeting rooms, } \\
\text { group decision } \\
\text { support systems }\end{array}$ & $\begin{array}{l}\text { Remote Interaction: } \\
\text { e.g. Audio } \\
\text { telephone) } \\
\text { conferencing, Video } \\
\text { conferencing, media } \\
\text { space }\end{array}$ \\
\hline $\begin{array}{l}\text { Different } \\
\text { time } \\
\text { (asynchro } \\
\text { nous) }\end{array}$ & $\begin{array}{l}\text { Ongoing tasks: } \\
\text { e.g. team } \\
\text { rooms, group } \\
\text { displays, project } \\
\text { management }\end{array}$ & $\begin{array}{l}\text { Communication and } \\
\text { coordination: e.g. } \\
\text { Voice mail, } \\
\text { Electronic mail, } \\
\text { Computer } \\
\text { conferencing, } \\
\text { Groupware } \\
\text { (Intranets) }\end{array}$ \\
\hline
\end{tabular}

Table 1: Array of communication technologies (based on Johansen's typology cited by Kimbal, 1997).

For a virtual community of researchers, the most likely scenarios are cases with different place and same/different time. Choosing which media among the technologies will be based on the particular purpose of the group's goal and the effect the group wants and needs. The use of diverse media can achieve powerful effects at different times. Moreover, different media have different issues to consider. Kimball [10] noted that for electronic mail, norms for things such as e-mail style, response time, copied and/or blind copies, need to be established. For decision making support systems, are the group members able to contribute anonymously, and what is the validity of the computer process? For audio conferencing, it is important to help participants have a sense of who is "present" and to promote balanced participation. For video conferencing, it is necessary to manage the attention span of participants and make use of the video channel effectively. For asynchronous web-conferencing, relevant issues include allowing group members to participate at different times, and creating a mental map to build a culture. Lastly, for document sharing, group members are required to develop relationships and affective qualities like trust.

Design for collaboration should support collaboration at any time, place, or level. The interactions that occur in the virtual environment can be a cascade of events. Casual personal interaction can turn into informal collaborations, which may then turn into formal meetings and/or continuous work plans. The virtual environment should be able to handle a variety of interactions to support all types of collaboration.

\section{Recommendation Of Design Of Future Systems: proposed prototype - the Commons}

Needs-Based Evolution. In most cases where a socalled virtual community comes to work, the site is defined before the community, in a sort of "wouldn't it be neat if..." scenario. In the virtual community of researchers that we are developing, the initial user group is well known and defined, and, at this point, exclusive. It is not yet a "community" in the common social sense of casual interaction. It does not (yet) have that flavour of old style BBSes, although this may emerge over time. The preferred means of group interaction is still email.

The lab site for the virtual community is driven by functional goals for service delivery to the subgroups within the group, rather than by social goals that facilitate virtual interactions. Some of our goals include convenient file dissemination across heterogeneous computing environments (and computing literacies), scheduling/meeting updates, ready access to previously developed materials, easy annotation of these materials, and on-the-fly summation of these materials at various levels (from executive summary to complete report).

The user group meets physically in its entirety on a regular basis. The site therefore acts as a reference point for one subgroup to post its work in progress for the other groups' interest and points in common. There is no insistence that the site evolve as a communal entity. 
In a sense, we are waiting to see if our evolving needs either require or become this.

In other words, our approach is not to develop features in advance of a group request for a feature. For instance, our first "need" arose when we as a group decided that email attachments of files were a considerable annoyance. While easy to add an attachment to an email in most email systems, such files are not easy to maintain, and are a drain on system resources if one is on a modem line rather than a high speed internet connection. The simple solution seemed to be: put your paper on your web site and include a URL in your email. In many mailers, URLs show up in mail as links, and it is simple to click on the link and go directly to the paper. We also decided that pdf should be the default format for document uploads since the Reader software comes with most browsers and allows documents to be viewed, with formatting from anywhere a browser has the reader installed. These files can be downloaded, too.

The immediate problem became that a large number of the group did not know nor care to know how to deal with uploading documents. Also, simply uploading a document and viewing a directory list of files does not tell a user very much about the file. The need defined, we could build a web page to allow password-protected access to the file upload area, present the user with a form to give the paper a meaningful title, include an abstract about the paper, and have a link automatically created to the file via the title. The resulting functionality presents a user with an annotated list of linked papers. The next step will be to add a sorting feature to the page to allow the list to be viewed by other criteria.

Features are added to the site on an "as-needed" basis. Once created, features can then be tweaked or modified according to how well their implementations are received by group members.

As described above it is easy to see that we are only in the initial stage of virtual community evolution. We have the start of a virtual workspace where work is represented there, but not yet done there. It's current communal attribute is that work is represented there for the collaborative benefit of the Lab/Projects/Members associated with this community.

One may wonder therefore how this site is different from any other web site that archives group materials and has a scheduler, like most groupware. Perhaps the key difference is that the site is dynamic in the sense that we are letting the evolution of our Lab drive the evolution of the site. We are open to it requiring either more features or more refinement to the current features. In most web sites, there is effectively a one-to-many relationship of one webmaster updating a site for all users. In our case there is a loose infrastructure that facilitates each subgroup to maintain their component of the site. The site's automation also encourages members of the group's groups to feel free to add components to the site at any time. One of our goals is to improve the level of ease with which members can update material so that the site becomes a more active hub of activity. Ease of use is crucial since the postings themselves keep each group apprised of their ongoing work, and synergies that come from such awareness may be crucial to the Lab's survival

We are also focussing on issues of how to personalize and customize different areas within the site for different subgroups and topics. This includes the use of tools for creating new labs and projects within the community and for regulating access by different user groups to different areas within the site.

\section{Conclusions}

We are in the preliminary stages of our work, both in building the infrastructure for our extended (into the virtual) Lab space/community, and for observing its effects on community growth. Based on our experiences, and review of the available literature, we suggest that virtual community builders act to find the best ways to sustain the needs of an existing real community. This precept is not new, as the success of Newsgroups and AOL chat spaces shows: if there are a handful of people or more devoted to a topic, there will be a newsgroup to support the exchange of information about that topic. Similarly research on virtual worlds/virtual communities shows that where infrastructure of a "world" exists without a community first, attendance in that space tends to fall off within a few weeks.

From this work, we hope to be able to build an infrastructure and suite of tools that can be called upon at any time by other such virtual Labs, customizable on demand for their needs. We want to build environment components that facilitate Lab growth in series from Lab, Project to Researcher levels. We suspect that by starting from the larger frame's needs and working down to the individual user's needs within this space, that identities will have the opportunities to evolve along with the specific work practices (idiosyncracies) of the group itself. Rather than impose structure upon the virtual Lab space from the outset, we want to support the evolution of its own gradations of structure, cohesion, and hence community dynamism. 


\section{Acknowledgments}

This research was supported by funding from the Bell Canada University Laboratories.

\section{References}

[1] Toomey, L., Tang, JC., Mark, G., Adams, L. (1998) "Designing Virtual Communities for Work" SIGGroup Bulletin, December, vol 19, No. 3, pp6-7.

[2] Koku, E., Nazer, N., Wellman, B. (1999). "Netting Scholars: Online and Offline" American Behavioral Scientist: Special Issue: "Mapping Globalization 2000", Vol 43, October 1999.

[3] McGrath, A., (1998) "The Forum" SIGGroup Bulletin, December, vol 19, No. 3, pp21-25.

[4] Boetcher, S. "What types of virtual communities can I build and what tools are available?" May 26, 1999 <http://www.fullcirc.com/community/communitytypes.htm $>$ (December 4, 1999).

[5] Alwang, G. "Instant Groupware" February 10, 1998 <http://www.zdnet.com/pcmag/features/teamware/_open.ht $\mathrm{m}>$ (December 4, 1999).

[6] Sidhu, C.K., and Bowman, P. (1999) "Real People in Surreal Environments" In: P.J. Sheppard and G.R. Walker (eds): Telepresence, Kluwer Academci Publishers, Netherlands, pp.244-262.

[7] Schrage, M. (1990) "Shared Minds" Random House Inc., New York.

[8] Kimball, L (1997) “Managing Virtual Teams" Team Strategies Conference, Toronto.

[9] Baecker, R.M., Grudin, J., Buxton, W.A.S., Greenberg, S. (1997). "Groupware and ComputerSupported Cooperative Work" In: R.M. Baecker, J. Grudin, W.A.S. Buxton, S. Greenberg (eds): Readings in Human-Computer Interaction: Toward the Year $20002^{\text {nd }}$ edition, Morgan Kaufmann Publishers, Inc.

[10] Kimball, L "Choosing media strategically for team communications" $\quad$ February $24, \quad 1998$ <http://www.tmn.com/ lisa/teams/choices.htm> (December 4, 1999).

\section{Authors' Biography}

dr. m.c. schraefel is an assistant professor in Human Computer Interaction in the Computer Science Department, University of Toronto, Canada.

Janet Ho is completing her Masters of Applied Science in Department of Mechanical and Industrial Engineering at the University of Toronto, Canada.

Dr. Mark Chignell is an associate professor of Mechanical and Industrial Engineering, and is the head of the Interactive Media Lab at University of Toronto, Canada.

Michael Milton works in the Strategy and Expernal Research group of Bell Canada and is responsible for the Bell Canada University Labs research program at the University of Toronto. 